\title{
Big cat in well: an unconventional threat to leopards in southern India
}

\author{
Sanjay Gubi, Aparna Kolekar, Pallabi Chakraborty and Vijaya Kumara
}

\begin{abstract}
The Vulnerable leopard Panthera pardus is declining as a result of poaching, habitat loss, retaliatory killing and collisions with vehicles. In the southern Indian state of Karnataka there is also an unconventional threat that has received little attention: leopards accidentally falling into unsecured open wells. During 2008-2017 there were 70 incidents of leopards falling into wells, in 10 of 30 districts, with the greatest number recorded in Udupi district (46\%). Leopards were released at the site $(40 \%, \mathrm{n}=28)$, or assisted to escape on their own or were translocated after rescue $(41 \%, n=29)$. Eleven per cent $(n=8)$ of the leopards died as a result of the fall, and $7 \%(\mathrm{n}=5)$ were sent to zoos, with serious injuries. The highest number of falls occurred during the pre-monsoon and monsoon seasons in districts with high rainfall, which may curtail visibility. Open wells are an emerging threat to the leopard and other animal species, and require covers and the security of a parapet.
\end{abstract}

Keywords India, leopard, open well, Panthera pardus, spatio-temporal trend, threats

he Vulnerable leopard Panthera pardus is highly resili-
ent and adaptable, surviving in diverse habitats, includ-
ing in human-dominated landscapes (Daniel, 2009) where it
depends on food sources such as domestic dogs and live-
stock (Athreya et al., 2016). Although widely distributed,
leopard populations are declining across the species' range
as a result of habitat loss, prey depletion, poaching, re-
taliatory killing and collisions with vehicles (Gubbi et al.,
2014; Jacobson et al., 2016). In India, leopards are found in
multiple-use forests, rocky outcrops, and communal and
private lands (Gubbi et al., 2017). In areas with dense
human populations, where water wells are abundant, leo-
pards have accidentally fallen into open wells while chasing
prey or running away from people (Ghule et al., 2014). These
unsecured structures are a danger to humans and wildlife,
and there are reports of leopards dying as a result of falling
into these open wells (Athreya et al., 2015). As the extent of

SANJAY GuBBi ${ }^{*}$ (Corresponding author) Aparna Kolekar and Pallabi Chakraborty Nature Conservation Foundation, 1311, $12^{\text {th }}$ Main Vijayanagara, Mysore, 570 017, India. E-mail gubbi@ncf-india.org

VIJAYA Kumara Department of Wildlife \& Management, Kuvempu University, Shankarghatta, India

*Also at: Department of Wildlife \& Management, Kuvempu University, Shankarghatta, India

Received 24 January 2019. Revision requested 26 February 2019. Accepted 5 March 2019. First published online 14 October 2019. this unconventional threat was not previously known, we examine the spatio-temporal trends of leopard falls into open wells, report the outcomes of the falls, and make recommendations for mitigating this emerging threat.

Our study area comprises the $191,791 \mathrm{~km}^{2}$ of the state of Karnataka in southern India, with its 30 administrative districts and 176 subdistricts or taluks. Land cover comprises forests, agro-forest plantations, rocky outcrops, grasslands, urban areas and agricultural land (Roy et al., 2015).

We collated data from vernacular (Kannada) and English media reports from 2008 to 2017 , and obtained Forest Department records for 2008-2014. We also collected forest cover data from the Karnataka Forest Department. We segregated information on date and location of leopard falls into open wells, the condition of the wells, and outcomes. We classified the seasons as winter (January-February), pre-monsoon (March-May), monsoon (June-September) and post-monsoon (October-December), following Kotahwale \& Rajeevan, 2017. We used administrative districts as the geographical unit of analysis. We mapped the distribution of leopard fall incidents for June 2008-December 2017, using ArcGIS 10.1 (Esri, Redlands, USA), on the forest cover layer for Karnataka state.

During the 10 years 2008-2017, 70 incidents were recorded in 10 districts of Karnataka (Fig. 1), with the highest number (46\%) in Udupi district. There was an increase from two incidents in 2008 to 16 in 2015, and a decline thereafter (Fig. 2). The greatest number of incidents occurred in the monsoon season (Fig. 3). All the wells were unsecured and open, and many $(49 \%)$ did not have stairs or a platform that would allow an animal to escape. Out of the 31 incidents for which data on the rescue methods were available, rescues were carried out using a ladder, nets or cages in 26 cases ( $83.9 \%$ ), following sedation of the leopard using a tranquilizing gun in four cases (12.9\%), and in one incident (3.2\%) the leopard was scared out of the well using a fire torch. Twenty-nine (41\%) of the leopards were translocated after medical inspection and treatment, if required, $28(40 \%)$ were released at the same site or were assisted to escape on their own, eight $(11 \%)$ died as a result of the fall and five ( $7 \%$ ) were sent to zoos, with serious injuries.

From the same media sources we also recorded 27 incidents of other wildlife species falling into open wells during the same period, including Bengal fox Vulpes bengalensis, sloth bear Melursus ursinus, small Indian civet Viverricula indica, elephant Elephas maximus, gaur Bos gaurus, sambar Rusa unicolor, black buck Antilope cervicapra, chital Axis axis, muntjac Muntiacus vaginalis and mugger crocodile Crocodylus palustris. These incidents resulted in 11 mortalities. 


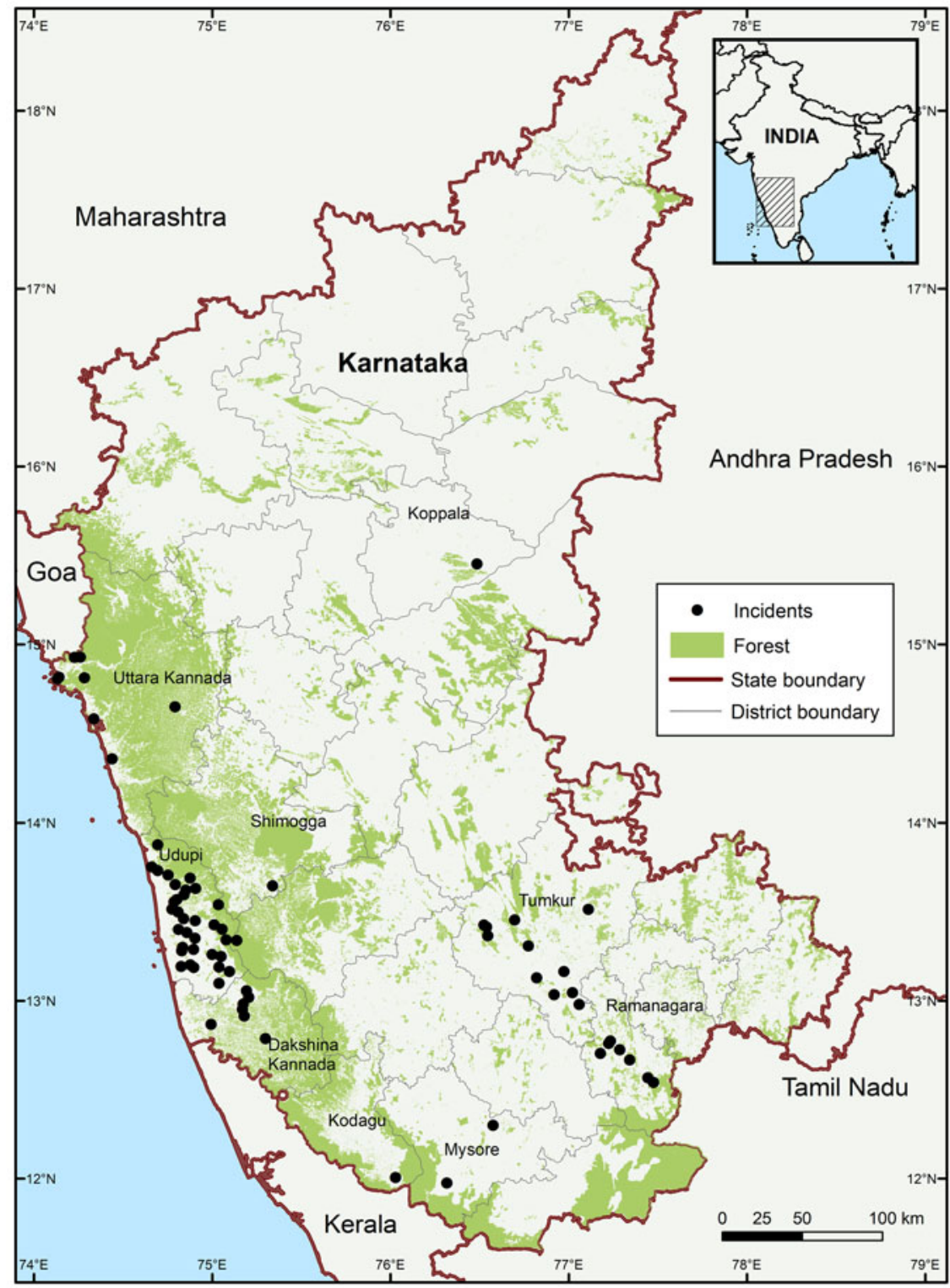

FIG. 1 The distribution of incidents of leopards Panthera pardus falling into unsecured open wells $(n=70)$ in the state of Karnataka, India.

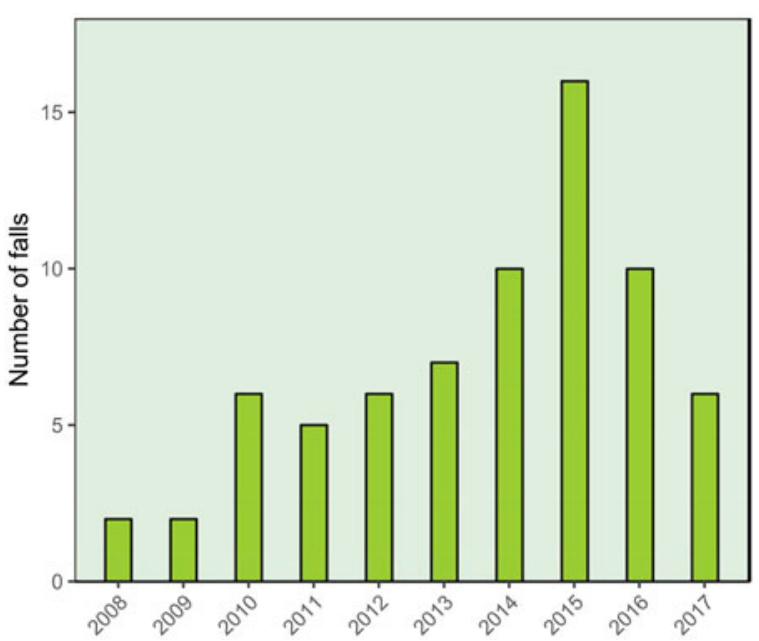

FIG. 2 The number of leopards per year falling into open wells $(\mathrm{n}=70)$ in Karnataka (Fig. 1) during 2008-2017.
To our knowledge this is the first compilation of information on leopards falling into open wells. In comparison, there were a total of 23 leopard mortalities as a result of collisions with vehicles in Karnataka over 5 years (July 2009-June 2014; Gubbi et al., 2014), and Athreya et al. (2015) reported nine leopard deaths as a result of poaching and two as a result of retaliatory killing over a 12-month period (May 2013-April 2014). Our findings indicate that mortality and injury of leopards falling into open wells is an emerging threat. As with other unnatural causes of mortality, this is a cause for concern.

The greatest number of incidents occurred during the monsoon season, possibly as a result of the lower visibility at this time. The districts with the highest incidences (Udupi, Dakshina Kannada and Uttara Kannada) receive high rainfall (annual totals of c. 4,000, 3,600 and 2,600 mm, respectively). These three districts are geographically 


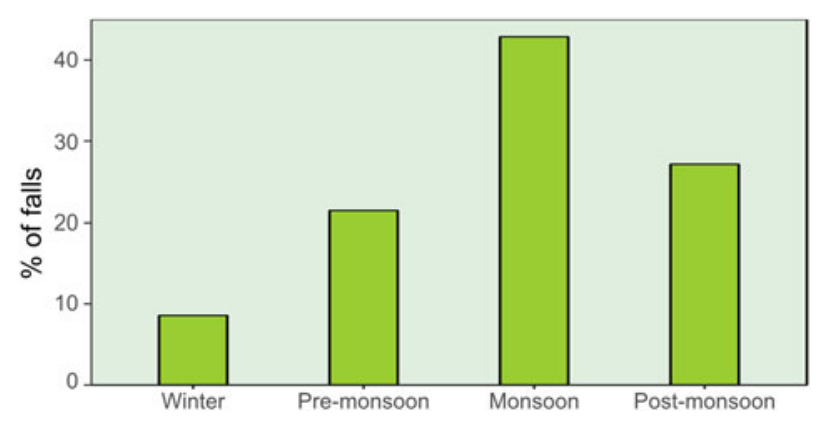

FIG. 3 Per cent of the toal number of leopards $(n=70)$ falling into unsecured open wells in each of the four seasons in Karnataka during 2008-2017.

contiguous. That not all falls into open wells resulted in injury or death may be a result of the high water levels in the wells during the monsoon season, as leopards swim reasonably well and thus may have saved themselves from drowning.

In most incidents the forest department rescued the leopards, although in a few cases the general public undertook the rescues when the department did not respond in a timely manner. These falls can lead to stress, injury and death of the leopard, and also pose a risk to people if the leopard manages to escape from the well. Media reports indicated that people were largely cooperative with the relevant authorities in most of the incidents, although in some cases negative reactions that resulted in injury to the leopard were recorded.

Leopards have a varied diet, including domestic animals (Athreya et al., 2016), and they roam into human-dominated areas, especially farmlands, where there may be unsecured open wells. The responsibility of covering and securing these open wells with a parapet should fall to the forest department's community conservation initiatives, such as Joint Forest Management Committees and Eco-development Committees, and to the Compensatory Afforestation Fund Management and Planning Authority.

To prevent harm to either people or leopards during the rescue of leopards from open wells the forest department requires appropriate equipment, the ability to respond in a timely manner, and crowd handling skills. The audiovisual guidelines for safely handling leopards occurring in densely populated areas (Gubbi et al., 2016) could be adopted in states where such incidents occur.

The leopard was recently uplisted from Near Threatened to Vulnerable on the IUCN Red List, with documentation of some region-specific threats in India (Jacobson et al., 2016). With India comprising $>75 \%$ of the extant range of Panthera pardus fusca (Jacobson et al., 2016), any emerging threats need to be documented. As far as we are aware, falling into open wells is not a risk for other leopard subspecies but, with leopards being increasingly documented in human-settled areas, any open wells will need to be securely covered to prevent any increase in this emerging threat.

Acknowledgements We thank the Karnataka Forest Department for providing the data on leopard fall incidents and other support the Central Ground Water Board for providing data on open wells, and a Kaplan Graduate Fellowship and Whitley Fund for Nature for financial support.

Author contributions Conceptualization: SG; data collection: AK, SG; data processing and analysis: AK, PC, SG; writing: all authors.

\section{Conflicts of interest None.}

Ethical standards This research abided by the Oryx guidelines on ethical standards and did not involve human subjects, experimentation with animals and/or collection of specimens.

\section{References}

Athreya, V., Odden, M., Linnell, J.D.C., Krishnaswamy, J. \& Karanth, K.U. (2016) A cat among the dogs: leopard Panthera pardus diet in a human-dominated landscape in western Maharashtra, India. Oryx, 50, 156-162.

Athreya, V., Srivathsa, A., Puri, M., Karanth, K.K., Kumar, N.S. \& KARANTH, K.U. (2015) Spotted in the news: using media reports to examine leopard distribution, depredation, and management practices outside protected areas in southern India. PLOS ONE, 10, eo142647.

Daniel, J.C. (2009) The Leopard in India: a Natural History. Natraj Publishers, Dehradun, India.

Ghule, A., Athreya, V., Linnell, J., Odden, M. \& Lenin, J. (2014) Waghoba Tales: Adventures in Leopard Land. NINA Special Report 58. Norwegian Institute for Nature Research, Trondheim, Norway.

Gubbi, S., Nagashettihalli, H., Bhat, R., Poornesha, H.C., Anoop, A. and Madhusudan, M.D. (2017) Ecology and Conservation of Leopards in Protected and Multiple-Use Forests in Karnataka. Nature Conservation Foundation, Mysore, India.

Gubbi, S., Poornesha, H.C., Daithota, A. \& Nagashettihalli, H. (2014) Roads emerging as a critical threat to leopards in India. Cat News, 60, 30-31.

Gubbi, S., Poornesha, H.C., Nagashettyhalli, H. \& Kolekar, A. (2016) Safely Handling Situations When Leopards Enter Human

Dense Areas. Nature Conservation Foundation, Mysore, India.

Jacobson, A.P., Gerngros, P., Lemeris, Jr, J.R., Schoonover, R.F., Anco, C., Breitenmoser-Würsten, C. et al. (2016) Leopard (Panthera pardus) status, distribution, and the research efforts across its range. PeerJ, 4, e1974.

Kothawale, D. R. \& Rajeevan, M. (2017) Monthly, Seasonal and Annual Rainfall Time Series for All-India, Homogeneous Regions and Meteorological Subdivisions: 1871-2016. Report No. RR-138, ESSO/IITM/STCVP/SR/o2(2017)/189. Indian Institute of Tropical Meteorology, Pune, India.

Roy, P.S., Behera, M.D., Murthy, M.S R., Roy, A., Singh, A., Kushwaha, S.P.S. et al. (2015) New vegetation type map of India prepared using satellite remote sensing: comparison with global vegetation maps and utilities. International Journal of Applied Earth Observation and Geoinformation, 39, 142-159. 